Article

\title{
Key Competencies for Design in a Circular Economy: Exploring Gaps in Design Knowledge and Skills for a Circular Economy
}

\author{
Deborah Sumter*(D), Jotte de Koning, Conny Bakker and Ruud Balkenende \\ Faculty of Industrial Design Engineering, Delft University of Technology, 2628 CE Delft, The Netherlands; \\ jotte.dekoning@tudelft.nl (J.d.K.); c.a.bakker@tudelft.nl (C.B.); a.r.balkenende@tudelft.nl (R.B.) \\ * Correspondence: d.x.sumter@tudelft.nl; Tel.: +31-616-635-116
}

check for

updates

Citation: Sumter, D.; de Koning, J.; Bakker, C.; Balkenende, R. Key Competencies for Design in a Circular Economy: Exploring Gaps in Design Knowledge and Skills for a Circular Economy. Sustainability 2021, 13, 776. https://doi.org/10.3390/su13020776

Received: 4 December 2020

Accepted: 12 January 2021

Published: 14 January 2021

Publisher's Note: MDPI stays neutral with regard to jurisdictional claims in published maps and institutional affiliations.

Copyright: (c) 2021 by the authors. Licensee MDPI, Basel, Switzerland. This article is an open access article distributed under the terms and conditions of the Creative Commons Attribution (CC BY) license (https:// creativecommons.org/licenses/by/ $4.0 /)$.

\begin{abstract}
In a recent study, we identified seven key circular competencies for design: (1) Design for Multiple Use Cycles, (2) Design for Recovery, (3) Circular Impact Assessment, (4) Circular Business Models, (5) Circular User Engagement, (6) Circular Economy Collaboration, and (7) Circular Economy Communication. These were derived from small-scale studies with designers working in the Netherlands. We set out to assess to what extent this set of seven competencies is recognized by an international group of designers and to evaluate whether any competencies are missing. We used an online survey to collect data from 128 respondents from 25 countries working on circular economy projects. The survey results showed that respondents use and have expertise in all seven competencies and they stressed the practical importance of two new competencies: Circular Systems Thinking and Circular Materials and Manufacturing. The resulting set of nine key competencies is the first internationally verified, coherent set of key circular economy competencies for design. This set will strengthen the pedagogical base of design for a circular economy and will guide the development of circular design methodology.
\end{abstract}

Keywords: circular economy; circular design; product design; competencies; design education; sustainability

\section{Introduction}

The circular economy is an alternative to the linear economy. It emphasizes making more effective use of resources by closing and slowing resource loops [1] thereby creating a system without waste and emission [2]. Research has shown that better design can assist in closing and slowing loops [3,4]. Moreno et al. [5] state that designers have a significant responsibility for shaping how products and services are built. The design decisions we take now will greatly impact future product recovery [6].

Design for a circular economy (DfCE) aims to maximize the length of product integrity [7]. Following the inertia principle [8], value recovery strategies aimed at maintaining integrity on a product level (i.e., repair, refurbishment, and remanufacturing) are prioritized over those that work on a material level (i.e., recycling). We frame DfCE as a field within the design for sustainability domain. Similar to other design for sustainability approaches such as eco design [9], nature inspired design [10] and transition design [11], DfCE aims to contribute to sustainability. What differentiates DfCE from other design for sustainability approaches, is its emphasis on high value, quality cycling of materials [12] and its use of circular business models [1].

A circular economy requires new competencies $[13,14]$. We define competency as: "a functionally linked complex overview of knowledge, skills, and attitudes that enable successful task performance and problem solving" [15]. Research suggests that competencies can inform the development and use of methods and vice versa [16,17] as well as informing the discourse of education. For instance, UNESCO [18] uses key sustainability competencies $[15,19,20]$ to frame learning objectives for education for Sustainable Devel- 
opment. Education plays an important role in driving the transition toward a circular economy [21,22], making it relevant to further investigate circular economy competencies.

In a recent study, we derived an overview of seven circular economy competencies for design [23]: (1) Design for Multiple Use Cycles, (2) Design for Recovery, (3) Circular Impact Assessment, (4) Circular Business Models, (5) Circular User Engagement, (6) Circular Economy Collaboration, and (7) Circular Economy Communication (Table 1). These were categorized using a general sustainability framework [15], see Table 1. This overview was the result of a series of studies in which we compared findings from literature with practice [23-25] and interviewed several designers predominantly working in the Netherlands.

Table 1. Circular economy competencies for design categorized following the Wiek et al. [15] sustainability competencies framework.

\begin{tabular}{l}
\hline Circular Economy Competencies for Design [23] \\
No specific competencies identified \\
\hline Design for Multiple Use Cycles \\
Foreseeing the consequences of prolonged use and multiple use cycles \\
Design for Recovery \\
Incorporating recovery strategies during the design process while \\
taking into account multiple use cycles
\end{tabular}

\section{Circular Impact Assessment \\ Estimating the environmental impact of circular offerings on a system level over multiple life cycles to support decision-making during the} design process

Sustainability Competencies [15]

Systems thinking competency

" $(\ldots$. $)$ the ability to collectively analyze complex systems across different domains (society, environment, economy, etc.) and across different scales (local to global) (...)." (p. 207)

\section{Circular Business models}

Concurrently developing the circular product, service, and business model

Circular User Engagement

Engaging users in the use and the (end-of-use) return of products

Anticipatory competency

"the ability to collectively analyze, evaluate, and craft rich 'pictures' of the future related to sustainability issues and sustainability problem-solving frameworks" (p. 209)

\section{Normative competency}

"the ability to collectively map, specify, apply, reconcile, and negotiate sustainability values, principles, goals, and targets" (p. 209)

\section{Strategic competency \\ "the ability to collectively design and implement interventions, transitions, and transformative governance strategies toward sustainability." (p. 210)}

\author{
Circular Economy Collaboration \\ Identifying, mapping, facilitating, and managing the collaboration \\ between external stakeholders in operationalizing a circular \\ business model \\ Circular Economy Communication \\ Telling coherent stories about the circular offerings
}

\author{
Interpersonal competency \\ "the ability to facilitate collaborative and \\ participatory problem solving, while ensuring a \\ respective and empathetic exchange of perspectives and \\ actions and dealing with conflict resolution." (p. 211)
}

In this study, we will assess the extent to which these seven competencies are recognized by an international group of designers and evaluate whether any competencies are missing from the overview. To achieve this, we conducted a survey in which we asked respondents how often they used these competencies, how they assessed their expertise in using them and which other competencies they used. The literature suggests that the need to acquire a competency varies according to the role or profile of the designer (e.g., de Los Rios and Charnley [26] and Sumter et al. [24]), thus we also looked at the influence of factors such as the professional background and work environment of the respondents.

\section{Research Method}

A survey was conducted to understand the use of and expertise in circular economy competencies for design, in practice. 


\subsection{Survey}

The seven circular economy competencies for design (Table 1) form the foundation for the survey. We followed the cycle of constructing an effective survey as formulated by Peterson [27]: we determined which (types of) questions we should ask based on the study's objective. We then reviewed the specific wording and the order of the questions, and pretested the survey. In the survey we phrased the competencies in less academic wording, for example, we referred to "design skills for a circular economy" instead of "circular economy competencies for design". We tested whether the newly formulated competencies were interpreted as intended with a with a small sample of design professionals. Table 2 gives an overview of the competencies as formulated in previous studies and the re-formulation for the online survey. The full online survey can be found at https:/ / doi.org/10.4121/1321 3610.

Table 2. Descriptions of circular design competencies in survey.

\begin{tabular}{ll}
\hline & In Sumter et al. [23] \\
\hline Circular economy competencies for design \\
\hline Design for Recovery & $\begin{array}{l}\text { Incorporating recovery strategies during the } \\
\text { design process while taking into account } \\
\text { multiple use cycles. }\end{array}$ \\
\hline $\begin{array}{l}\text { Design for Multiple } \\
\text { Use Cycles }\end{array}$ & $\begin{array}{l}\text { Foreseeing the consequences of prolonged use } \\
\text { and multiple use cycles. }\end{array}$ \\
\hline
\end{tabular}

Estimating the environmental impact of circular offerings on a system level over multiple use cycles to support decision-making during the design process.

\section{In the Online Survey}

Design skills for a circular economy

You contribute to the development of products that can be repaired, refurbished, remanufactured, and/or recycled, or services that allow products to be refurbished, remanufactured, and/or recycled.

You design products that can be used over and over again, by the same or different users.

You measure the circularity of design solutions. For example, by using indicators such as 'recycled content' (i.e., the percentage of recycled materials used in a product), or repairability scores (i.e., the level of repairability of a product).

You design products that fit in a circular business model and vice versa. For example, when you design products fit for a leasing scheme you ensure that they can be repaired and maintained.

Concurrently developing the circular product, Circular Business
Model Integration service, and business model.
You design products and services that engage users in the circular economy. For instance, by developing services that allow the sharing of products or by creating products that are easy to maintain.

You engage and collaborate with many different stakeholders throughout the whole lifecycle of products and services. For example, you engage and collaborate with partners from recycling facilities to think about how products can be recovered at the end of the life.

You use storytelling and other communication strategies to engage stakeholders, colleagues and/or customers to join in on a circular economy. For instance, you use storytelling to create a shared circular economy vocabulary in your company.
Circular Economy Storytelling
Telling coherent stories about the circular offerings.
Identifying, mapping, facilitating, and managing the collaboration between external stakeho in operationalizing a circular business model.

The survey contained 37 open and closed ended questions. For each competency, we asked the respondents how often they used it (Use Frequency) and what their level of expertise (Self-Reported Expertise) was. The Use Frequency of the competencies was shown on a four-point Likert scale ( $1=$ never, $2=$ in one project, $3=$ in half of the projects, $4=$ in all projects). Self-Reported Expertise was shown on a five-point Likert scale ( $1=$ no experience, 2 = beginner, 3 = intermediate, $4=$ advanced, and 5 = expert). We used a five-point Likert 
scale on Self-Reported Expertise to give the respondents who had indicated to 'never' use a competency in a project (four-point Likert scale on Use Frequency) the opportunity to indicate that they had 'no experience'. The choice to include 'no experience' in the Likert scale on Self-Reported Expertise expanded the scale from 4 to 5 points. Respondents were also asked to give an example of how they applied each competency in their circular economy projects. This question was used to assess whether the respondent had interpreted the competencies as intended and to further understand their use in practice. Respondents were finally asked to describe additional competencies: competencies they used in practice, but not listed among the seven competencies in the survey. Last, respondents were asked to describe their professional background and work environment (e.g., company size, job title and whether they were involved in developing products, services, strategies, brands and/or buildings).

The survey was developed in Qualtrics XM (Qualtrics, Provo, UT) [28]. To test the survey, we first conducted a small-scale pilot with four design professionals from the target population. The survey was revised according to their feedback. Finally, a native Englishspeaking communication specialist checked the language before the survey was published.

\subsection{Respondent Recruitment}

Survey respondents were recruited via different channels. We directly contacted designers in our personal network by email and asked them to forward the survey to designers in their own network in order to benefit from snowballing. In addition, larger organizations such as the Ellen MacArthur Foundation and CIRCO (a Dutch governmentfunded program for companies interested in exploring circular economy opportunities) allowed us to share the survey in their networks. This was done via posts in their LinkedIn groups which focused on DfCE: 'Circular Design Guide' (18,526 members) and 'CIRCO creating business through circular design' (1205 members). We also shared the link to the survey in two other LinkedIn groups focused on designing and teaching for a circular economy: 'Circular Design: Learning for Innovative Design for Sustainability' (162 members) and 'Circular Economy Teaching and Learning' (3620 members). The survey was open for responses between 14 April and 22 May 2020.

\subsection{Data Analysis}

A total of 315 responses were recorded in Qualtrics. The survey included a check question to assess whether the respondents had worked on a circular economy project. We excluded 48 responses from the analysis when the respondents answered 'no' to the question 'Have you ever worked on a circular economy project?'. These 48 respondents did not get to see the rest of the survey. Instead, they were thanked for their contribution. In addition, we excluded another 121 respondents because their responses were not completely recorded i.e., we did not collect data about the use of and expertise in the competencies. Lastly, responses from 18 students were excluded as the study was aimed at design practice. This resulted in a total of 128 responses.

We used IBM SPSS Statistics Version 25 (International Business Machines Corporation, Armonk, New York, United States) to make a statistical overview of the demographic data, as well as the Use Frequency and Self-Reported Expertise. A one-way analysis of variance (ANOVA) was used to determine any statistically significant differences in the indicated Use Frequency and Self-Reported Expertise based on (1) the type of organization in which the respondents worked and the (2) years of experience they had. This enabled us to evaluate the effect of the professional background and work environment on the indicated Use Frequency and Self-Reported Expertise of the competencies. Finally, we established whether there was a correlation between the indicated Use Frequency and Self-Reported Expertise. An $\alpha$ value of $p<0.05$ was used to determine statistical significance.

The answers to the open-ended question "what skills are you missing" were analyzed and thematically clustered in order to identify potential new competencies, or to see whether we needed to adapt the descriptions of the original seven competencies. We 
used the definitions in Table 2 when clustering the answers. This process was guided by three questions: (1) does the description of this additional competency fit under one of the seven competencies in Table 2, (2) should the existing description of the competencies be expanded or changed, and (3) how should the description be adapted? This helped us assess whether the given examples were potential new additions to the set of seven competencies or whether the original descriptions needed to be adapted to more accurately reflect practice.

\section{Results}

We first present the professional background and working environment of the 128 respondents and then discuss the respondents' familiarity with the competencies. Finally, we present an overview of competencies perceived as missing from the original set by the respondents.

\subsection{Professional Background and Work Environment}

Of those respondents who reported their country of work $(n=97), 78 \%$ worked in Europe and the other $22 \%$ in the rest of the world ( 25 countries were represented in this sample). The most prominently represented European countries were the Netherlands $(38 \%)$, United Kingdom (12\%) and Germany ( $9 \%)$. Countries most prominently represented in the rest of the world were the United States of America (29\%), Australia (19\%) and India $(14 \%)$. Furthermore, most respondents were employed ( $84 \%)$, had a design background $(63 \%)$, worked in a large organization $(45 \%)$, and focused on developing products, services, and strategies. There was an even spread in work experience. Full details are shown in Figure 1A-D.

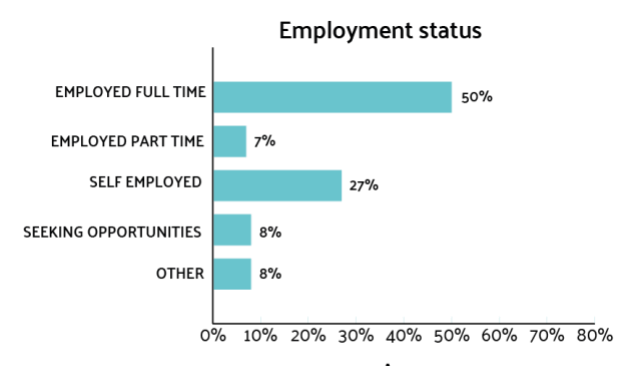

A

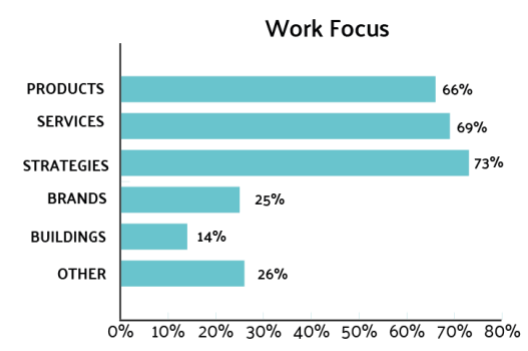

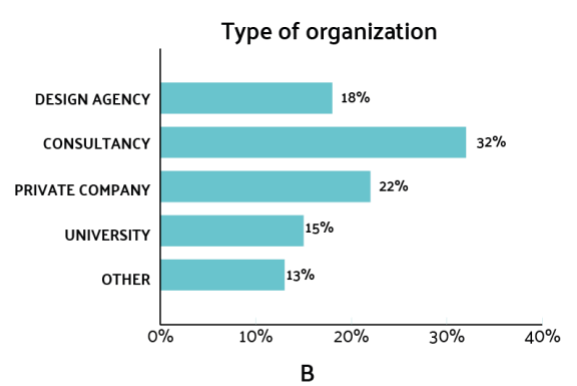

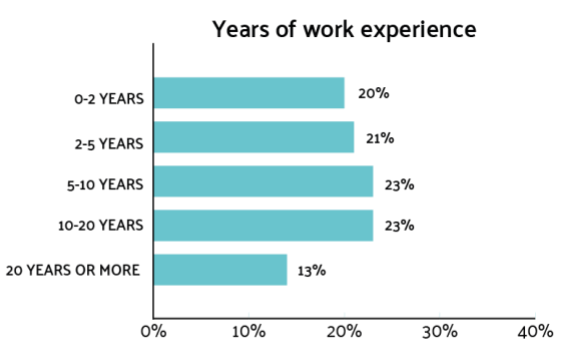

D

Figure 1. Professional background and work environment of the respondents represented in (A). Employment Status $(n=123)$, (B). Type of organization $(n=76),(\mathbf{C})$. Work Focus $(n=106)$, and (D). Years of work experience $(n=111)$.

Examples of other activities that respondents worked on included education, research, and relationship/partnership management. The main focus on products, services, and strategy was reflected in the project examples given: 'working on assessment tools for circular cities', 'developing biodegradable packaging for the food industry', 'closing the loop in the mattress industry', and 'stimulating mobile phone users to send back their products'. 


\subsection{Use of and Expertise in Circular Economy Competencies}

To assess the extent to which the competencies were recognized by an international group of designers, we analyzed the responses for Use Frequency and Self-Reported Expertise. The responses for Use Frequency for each of the seven competencies is shown in Figure 2A. With the exception of Circular Impact Assessment, more than $50 \%$ of the respondents indicated that they used each competency in half or all of their circular economy projects. The Self-Reported Expertise of the respondents per competency is shown in Figure 2B. There was a significant correlation between Use Frequency and SelfReported Expertise for each of the competencies. The correlation coefficients were positive and ranged between 0.65 and 0.83 . This implies that a higher Use Frequency goes hand in hand with a higher Self-Reported Expertise of the competency.

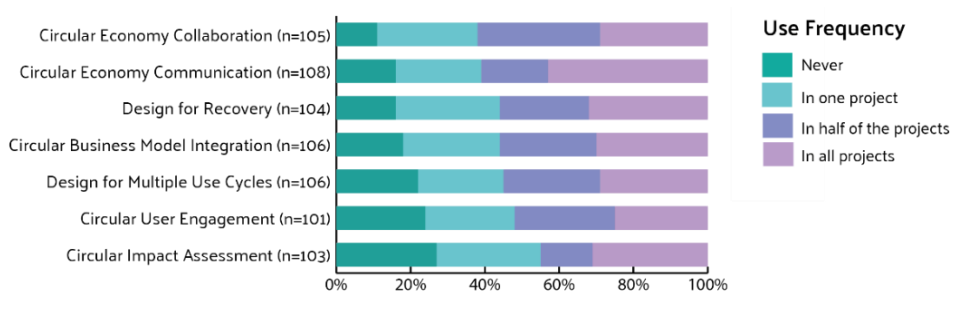

A

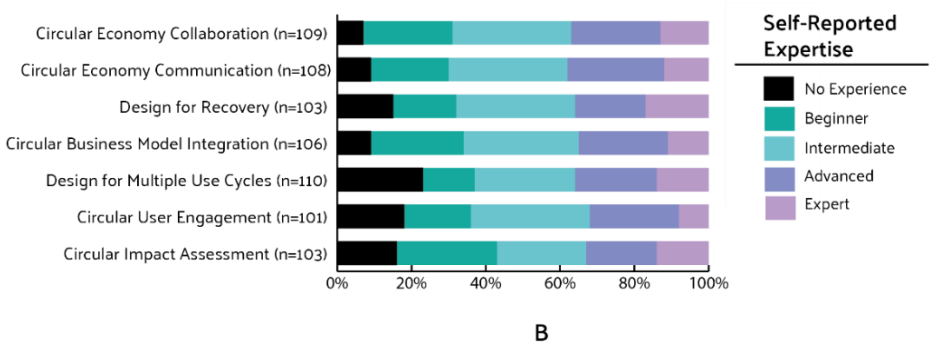

Figure 2. Distribution of response regarding (A) Use Frequency and (B) Self-Reported Expertise.

Figure 3 shows how many respondents used and had expertise in specific competencies. Of the respondents, $28 \%$ reported using all seven competencies and $37 \%$ reported having expertise in all seven competencies.
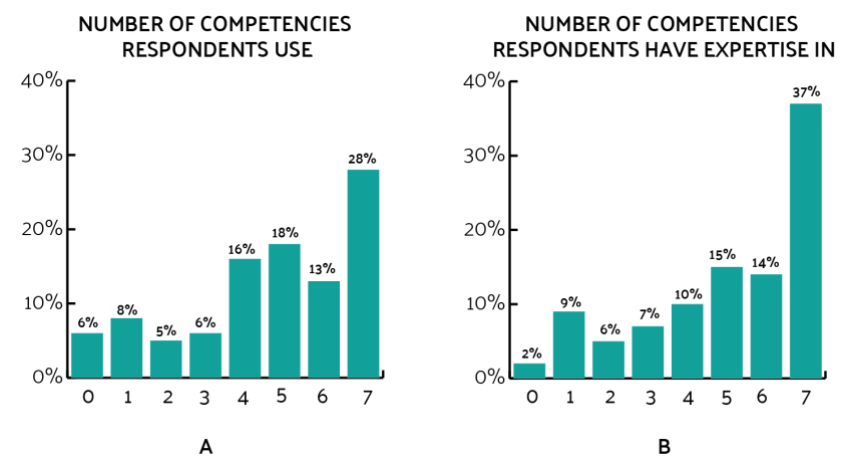

Figure 3. Distribution of the number of competencies respondents used (A) and distribution of the number of competencies respondents had expertise in $(\mathbf{B}) .0=$ none of the competencies used or no expertise. $7=$ all seven competencies used or expertise in all seven competencies.

We asked the respondents to give examples of how they used the competencies in practice. While not all respondents provided examples, we did collect a set of illustrative examples which reflected how the competencies were used in practice. These examples helped us understand whether the respondents had interpreted the competencies as intended and what knowledge they had regarding underlying concepts. Table 3 lists the 
examples, including quotes from the survey, and the approaches that the respondents used. The examples informed the adaptations we made to the descriptions of the competencies (see Section 4.2).

Table 3. Examples of use of competencies in circular economy projects.

\begin{tabular}{llll}
\hline Competency & $\begin{array}{l}\text { Examples of Use of Competencies } \\
\text { in Circular Economy Projects } \\
(n=\text { Number of Responses) }\end{array}$ & Quote
\end{tabular}

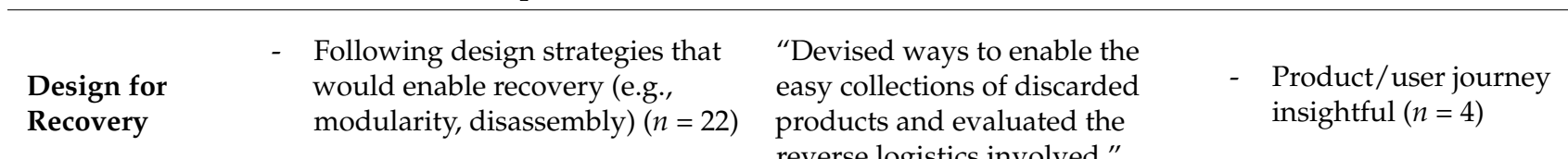

\section{- Focusing on services that keep} products in use longer $(n=13)$

\begin{tabular}{|c|c|}
\hline $\begin{array}{l}\text { Design for } \\
\text { Multiple Use } \\
\text { Cycles }\end{array}$ & $\begin{array}{l}\text { - Using circular design strategies } \\
\text { (e.g., timeless design, simple } \\
\text { design, design for durability, } \\
\text { design for disassembly) }(n=12) \\
\text { - Investigating changing user } \\
\text { needs }(n=9)\end{array}$ \\
\hline
\end{tabular}

reverse logistics involved."
"We have recreated our methodology in a way that our user journeys always have the possibility for multiple use cycles, over a single one."
- Creating project specific

Circular

Impact

Assessment indicators $(n=26)$

- Using existing environmental impact assessment tool and indicators $(n=24)$
- User journey mapping $(n=7)$
"We use a multi-criteria assessment including Circular Life Cycle Assessment (we developed our own circular LCA), Material Flow Analysis, Life Cycle Costing (together with our colleagues)."

\section{Circular \\ Business \\ Model}

Integration
"In product development we always make continuous [... ] serviceability evaluations."
- $\quad$ Life Cycle Assessment $(n=9)$

- $\quad$ Recycled content $(n=10)$

- Material passport $(n=3)$
- Circular/Sustainable Business model Canvas $(n=11)$

- Stakeholder dialogue/analysis $(n=7)$
- Making users experience the benefits of circular solutions (e.g. sharing pilots) $(n=12)$

Circular User

Engagement

- Focusing on customer benefits (e.g., ease of use, ease of repair) $(n=9)$
"I work with numerous groups to host sharing economy events-swap shops, repair cafes, promoting second hand shopping over fast fashion."
- User research via co-creation, diaries, surveys, and interviews $(n=13)$

- User journey mapping $(n=3)$
- Involving multiple partners (e.g.,

\section{suppliers, recyclers, and clients) in the early on in the development process $(n=47)$ \\ Circular \\ Economy \\ Collaboration}

"We look with partners at trade-in and buyback programs of IT servers and workstations, which also stimulates the Original Equipment

Manufacturer to launch certified pre-owned programs or re-use parts for repair."
- Co-creation, creative and brainstorming sessions $(n=12)$

- Surveys and Interviews $(n=7)$

- Stakeholder mapping and analysis $(n=4)$
- Giving examples of available circular economy through cases

Circular Economy Communication studies and physical prototypes $(n=21)$

- Creating shared understanding of purposes, needs and vocabulary $(n=19)$
"We are always asked to bring business cases to the table, or success stories".

"I designed a strategy to talk about transition. I created the visual language to make sure everybody was talking about the same thing." 
We asked the respondents which competencies they considered to be missing in the presented overview. They responded by giving 69 examples of which 58 were descriptions of competencies, the other 11 were related to character traits such as "perseverance or commitment". The 58 descriptions of the competencies were clustered as described in Section 4.1. Table 4 gives an overview of the resulting clusters, including illustrative quotes; most of which could be clustered under one of the seven competencies. We found two clusters that did not fit the existing competencies: Circular Systems Thinking and Circular Materials and Manufacturing.

Table 4. Clusters of respondents' additions to the seven circular economy competencies for design.

\begin{tabular}{|c|c|c|}
\hline Competencies & Quotes & Number of Respondents \\
\hline \multicolumn{3}{|c|}{ Competencies not mentioned in original set of seven } \\
\hline $\begin{array}{l}\text { Circular Systems } \\
\text { Thinking }\end{array}$ & $\begin{array}{l}\text { "[..] Being able to zoom in and zoom out on product and wider context." } \\
\text { "Learning to think about systems and how flows behave in them." } \\
\text { "A true market perspective [ . . . ] and clear business benefits-but } \\
\text { beware in the same time rebound effects and dangerous } \\
\text { growth promises." }\end{array}$ & 11 \\
\hline $\begin{array}{l}\text { Circular Materials } \\
\text { and Manufacturing }\end{array}$ & $\begin{array}{l}\text { "Materials and design; Material selection, design for manufacture or } \\
\text { disassembly, recycling material properties" } \\
\text { "Designing and technical production experience and knowledge is } \\
\text { needed before any circular solutions can be explored." }\end{array}$ & 10 \\
\hline \multicolumn{3}{|c|}{ Overlap with the original set of seven competencies } \\
\hline $\begin{array}{l}\text { Design for Multiple } \\
\text { Use Cycles }\end{array}$ & $\begin{array}{l}\text { "Design for modularity and pure material cycles." } \\
\text { "... in the building sector, we call it 'Design for Disassembly'—basically } \\
\text { designing buildings as elements, which could be reused as Lego". }\end{array}$ & 4 \\
\hline Design for Recovery & "Circular (reversed) logistics cost and organization." & 4 \\
\hline $\begin{array}{l}\text { Circular Impact } \\
\text { Assessment }\end{array}$ & $\begin{array}{l}\text { "We cannot forget to address ethical questions; what is the impact our } \\
\text { product has on users, producers, manufacturers, communities and } \\
\text { cultures." } \\
\text { "Integrating social and ecological domains in the circular economy by the } \\
\text { design of new products. i.e., how do you balance design to be good for } \\
\text { people, planet and profit." }\end{array}$ & 4 \\
\hline $\begin{array}{l}\text { Circular Business } \\
\text { Model Integration }\end{array}$ & "Business value (monetary impact) of circular economy projects." & 6 \\
\hline $\begin{array}{l}\text { Circular User } \\
\text { Engagement }\end{array}$ & $\begin{array}{l}\text { "So you have to be a designer, not only focuses on sustainability and } \\
\text { circular economy, because the users you are aiming for do not use/buy a } \\
\text { product just because it is circular." } \\
\text { "Consumer/stakeholder behavior change toward circularity." }\end{array}$ & 6 \\
\hline $\begin{array}{l}\text { Circular Economy } \\
\text { Collaboration }\end{array}$ & $\begin{array}{l}\text { "I notice it requires different techniques when working together in a } \\
\text { complex system with people with different expertise, like the circular } \\
\text { economy is." }\end{array}$ & 4 \\
\hline $\begin{array}{l}\text { Circular Economy } \\
\text { Communication }\end{array}$ & $\begin{array}{l}\text { "Educating those who are not familiar with the concept." } \\
\text { "Strategic alignment and visioning within corporations." }\end{array}$ & 9 \\
\hline
\end{tabular}

\subsection{Comparing Use Frequency and Self-Reported Expertise between Groups}

We found no significant differences in Use Frequency and Self-reported Expertise for most competencies based on the type of organization, the geographical location in which the respondents worked, or their years of experience. We performed one-way ANOVAs to test the assumption that the professional background and work environment influenced the Use Frequency of and Self-Reported Expertise in a competency. The exceptions are described below.

Respondents working for design agencies reported having a lower expertise in Circular Business Model Integration and Design for Recovery than respondents working at consultancies. Respondents with only a few years of work experience (i.e., $0-2$ years) reported lower expertise in Circular Economy Communication and Circular Business Model Integration than those who had greater experiences (i.e., 10 years or more). In addition, respondents work- 
ing for design agencies used Circular Impact Assessment less than those working for private companies and respondents working at consultancies used Circular Economy Communication less than respondents working at universities.

\section{Discussion}

We conclude our study with the addition of two competencies to our original list of seven key circular economy competencies for design: a total of nine. We first discuss the two additions made to the original set before reflecting on how we adapted some of the descriptions of the original competencies. We close with a discussion on the implications of our findings and opportunities for further research.

\subsection{Two Additions to the Original Set of Competencies}

We added two new competencies to the original set of seven: Circular Systems Thinking and Circular Materials and Manufacturing.

In the literature, Circular Systems Thinking is widely identified as an important competency for a circular economy (e.g., [3,29-31]). Yet, its actual use in practice was not evident in previous studies [23]. This survey, however, shows that systems thinking is also deemed important by practitioners. Respondents stressed the importance of "learning about systems and the flows within them" and "being able to zoom in and out" between the design of the physical product and the wider system. In the final set, we describe the competency Circular Systems Thinking as the ability to "adopt an approach to design that regards the circular economy as a complex system, taking into account that circular design interventions will have systemic effects". This description of the competency reflects the thought that circularity is not the property of an individual product or service but that of a system (Konietzko et al., 2020). In addition, this description of the competency signals the need to adopt a system-focus throughout the design process. This systems perspective is needed to both analyze which systems are needed to develop and operationalize circular products, services, and systems, and to assess the consequences of the circular design interventions on a wider system throughout and beyond the product-service life cycle. Systemic effects include, feedback loops, cascading effects, inertia, tipping points, causeeffects chains [15], and rebound effects [32].

Second, expertise related to Circular Materials and Manufacturing was indicated as an important additional competency. In the final set, we describe this competency as "the ability to select and use materials and manufacturing methods for a product to minimize the impact (environment, health, social), while taking the full lifecycle of the product and its recovery into account". We included Circular Materials and Manufacturing as a separate competency, as the focus on closing material resource loops lies at the heart of the circular economy. Respondents often mentioned the need for know-how about materials and manufacturing in connection with circular design strategies, such as regenerative design, design for the bio-cycle, and design for disassembly. The need for support when it comes to selecting and using materials is also recognized in the literature. In light of the future shortages of critical raw elements, Köhler et al. [33] called for designers to develop competencies around resource-aware product design. Lilley et al. [34] developed a framework on material change that helps designers gain more insights in the interaction between product use and material degradation. In addition, when it comes to limiting the impact of sourcing and recycling, the selection of suitable material and manufacturing processes is essential. Sauerwein and Doubrovski [35], for example, specified a process in which they used local recyclable bio-based materials as input in the additive manufacturing process. In short, Circular Materials and Manufacturing reflects a need in practice to align material and manufacturing choices with the chosen recovery opportunities.

\subsection{Adapting Competency Descriptions}

We evaluated and adapted the descriptions of the initial seven circular economy competencies in light of the results. We changed the description for all seven competencies 
from a process-oriented to a result-oriented description as this signals the end-goal instead of prescribing a potential path to reach that goal. In this section, we elaborate on and give reasons for the adaptation of each specific competency.

Design for Recovery is now described as "develop product-service systems that allow for products, components and materials to be recovered and looped back into a circular economy". The term product-service systems was explicitly chosen to signal that circularity goes beyond the design of a tangible product. Product-service systems are "a mix of tangible product(s) and intangible service(s) that are designed to jointly meet customer needs" [36]. The examples given by the respondents (Table 3) showed that this competency entails designing products and associated services so that they can be taken back and recovered (e.g., through repair, refurbishment, remanufacturing or recycling).

Design for Multiple Use Cycles has been rephrased "create product-service systems that are designed to have more than one use cycle while retaining value in a circular economy". We noticed an overlap in the interpretation of Design for Multiple Use Cycles and Design for Recovery suggesting that the original descriptions might not have been sufficiently distinctive. The rephrased descriptions of the competencies clarify that Design for Recovery focuses on the operations needed for recovery, while Design for Multiple Use Cycles focuses on the use cycles after recovery.

Circular Business Model (Integration) has been renamed Circular Business Propositions: "develop circular business propositions that aim at fully closing product and material loops and thereby keeping resources in use for as long as possible". Examples of the use in practice of this competency given in the survey, included exploring circular business model strategies. However, the given additional competencies (Table 4) reflected a need for assessing the business value as well as the regulations and policy necessary to ensure embedding of circular products services systems in practice. We chose Propositions as this better indicates the value that product-service systems can deliver to the user. It is a more general term that signals which and how value is created, while Circular Business Models points to a more specific detailing of how the value will be delivered and captured. Please note, however, that Circular Business Propositions are in line with circular business models. In the literature these are described as models that focus on slowing resources loops by prolonging the use of products and components in consecutive cycles, and closing resources loops by capturing end-of-life-material value [37,38].

The description of Circular User Engagement has been adapted to "engage users in all aspects of the circular economy, for instance by enabling users to share and care for (shared or owned) products and stimulate them to loop back products at the end of a use cycle". The examples given by the respondents (Table 3 ) suggest that some users might be reluctant to adopt circular product-service systems. As the dominant business models are those in which the ownership of the physical product is transferred to users, these same users are central when it comes to the voluntary return of products. Poppelaars et al. [39] argue that designers should be aware of the key steps in the divestment process in order to help users part with their product. Circular User Engagement highlights a new dimension of the design process as designers need to engage users in the circular economy and speed up the acceptance and adoption of both owned and access-based circular products.

For Circular Impact Assessment, we adapted the description to "measure the environmental, economic and social impact of circular design interventions throughout the full product-service life cycle". The examples of additional competencies given by respondents (Table 4) reflected a need to also include dealing with social, financial, and environmental consequences e.g., "balance design to be good for people, planet and profit" and "assessing the impact products have on users, producers, manufacturers, communities and cultures." The need to consider social impacts reflects the wider call in the literature to consider the social domain in the circular economy discourse [40,41].

Circular Economy Collaboration is now described as "facilitate and engage collaborations across value networks in order to create circular product-service systems and stimulate the transition toward a circular economy". Identifying which stakeholders should be involved 
is a crucial step to inform efforts around engaging and facilitating collaborations. The examples of how Circular Economy Collaboration was used in practice reflected that designers were involved in facilitating and engaging stakeholders who play a role across the full product-service life cycle to support the development and implementation of circular product-service systems. Additionally, the adapted description uses the term value networks as described by Brown et al. [42] to signal that a circular economy requires an eco-system in which multiple stakeholders collaboratively develop and operationalize circular products service systems.

Circular Economy Communication has been renamed Circular Economy Storytelling. Its description has been adapted to "create engaging visions and narratives of the circular economy in order to make it a shared idea for which support can be garnered among various stakeholders". Circular Economy Storytelling not only serves to convince peers to participate in developing circular product-service systems solutions, but also helps to gather support for circular strategies on an organizational level and embed circular practices in organizations. Lack of circular buy-in from stakeholders proved to be a challenge that prevented designers from moving forward with the implementation of circular product-services systems. In an earlier study, we noted that Circular Economy Communication was essential to support Circular Economy Collaboration, and we suggested that developing a circular economy vocabulary is an essential component to support this competency [25]. The literature also emphasizes the need for designers to develop futureoriented visions and narratives to guide sustainability transitions [11,43]. This supports the notion that designers could inspire and persuade other stakeholders to work toward building sustainable futures.

\subsection{A Coherent Set of Key Circular Economy Competencies for Design}

We validated a set of key circular economy competencies for design. In this section, we address the coherence of the set, we reflect on how it compares to other overviews of circular design competencies, and we address paths for future research.

Figure 4 shows the nine circular economy competencies for design. None of these competencies can be used in isolation, they form an interconnected set. The circular diagram shows that each competency is equally important. The icons form a visual representation of each competency, and similar colors were used to denote the relationships between competencies. Circular Systems Thinking argues that a systems approach is an essential element of the complete design process. Design for Recovery and Design for Multiple Use Cycles are competencies aimed at slowing and closing resource loops. These are also the 'newest' competencies, in the sense that the others (business proposition development, user engagement, materials and manufacturing knowledge, impact assessment, collaboration and storytelling) are recognizable for any design scholar- albeit in a circular context. However, Design for Recovery and Design for Multiple Use Cycles are at the heart of what a circular economy is about, which is slowing down and looping back the flows of products and materials in the economy. Circular Business Propositions, Circular User Engagement, and Circular Materials and Manufacturing enable the development process of circular productservice systems and reflect the integrative nature of design to connect business, users, and technology. Circular Impact Assessment guides the development of the design process and helps to determine the impact of the design interventions. Circular Economy Collaboration and Circular Economy Storytelling represent the interpersonal side of the design process i.e., involving and engaging stakeholders.

Our nine competencies differ from the circular economy competencies for design identified by De Los Rios and Charnley [26]. Ours are formulated so that they are result-driven and indicate how they are applied in practice. Our results show that the competencies form a coherent set. A substantial number of respondents used and had expertise in all of the seven original competencies. Professional background and work environment were shown to have little influence on the use of, or expertise in, a competency. With a few exceptions, there were no significant differences based on the type of organization and 
geographical location in which the respondents worked and their years of work experience, in contrast to suggestions in the literature e.g., [24,26]. This implies that all seven original competencies were used and considered valuable, independent of respondent background or work experience. Even though the competencies might not all be applied in each project, overall they reflect the main qualification of competent designers who specialize in DfCE.
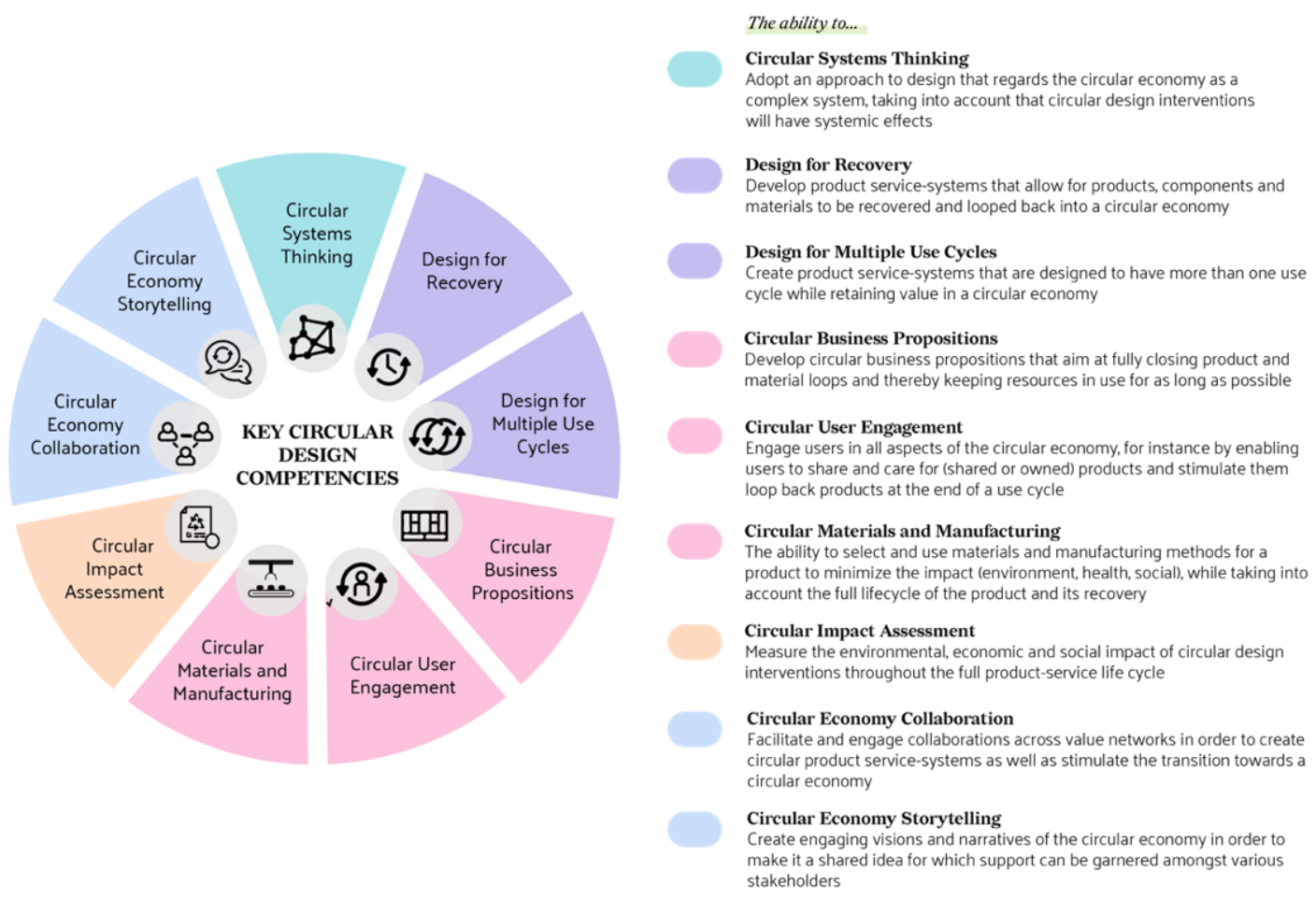

Figure 4. Nine key circular economy competencies for design (The circular design competency wheel).

Based on this research, we expect that acquiring these circular design competencies warrants the successful development and implementation of circular product-services systems. However, several barriers that persist outside the influence sphere of design need to be dealt with. Examples of these are financial (e.g., limited suitable sources for finance), operational (e.g., value chain management), and structural (e.g., lack of information) [44], but they can also be related to policy and legal frameworks [45].

Wiek et al. [46] detail a process for operationalizing competencies for different educational levels, which entails formulating learning outcomes and related concepts and methods. A similar process could be followed with the set of nine key circular economy competencies for design. This would be valuable when developing circular design methods and for curriculum development.

\section{Conclusions}

We conclude this study by presenting a set of nine key competencies for design in a circular economy: (1) Circular Systems Thinking, (2) Design for Recovery, (3) Design for Multiple Use Cycles, (4) Circular Business Propositions, (5) Circular User Engagement, (6) Circular Materials and Manufacturing (6) Circular Impact Assessment, (8) Circular Economy Collaboration, and (9) Circular Economy Storytelling. This internationally validated set of interlinked competencies provides a foundation for the growing interest in circular design competencies that support design practice and guide the development of design methods and courses in circular design. Our international survey with 128 respondents shows that the set is recognizable in practice. Ours is one of the first studies to provide empirical evidence for the need for such competencies. The results further indicate that the field is still relatively young, dynamic, and developing. We expect that in the future. designers 
will acquire more circular design expertise through practice which will enable them to better articulate the specific competencies they have acquired and still need, as well as which methods and educational programs could offer support. Therefore, we foresee that similar studies will be performed more regularly in the future to monitor the progress toward a circular economy and to understand the accompanying design competencies.

Lastly, while this set is not the 'final' answer in the search for circular design competencies, the international validation and consolidation of these nine key circular design competencies offers grounds for operationalizing them in practice; they serve as a foundation for the development of circular economy-based methodology and curricula.

Author Contributions: D.S. is the corresponding author of this manuscript and the primary author of this manuscript. She was in charge of collecting and analyzing the data, wrote the initial draft of the manuscript, and produced the tables and figures included in this manuscript. J.d.K., C.B. and R.B. supervised her in this process and contributed to reviewing the manuscript multiple times before it was submitted. All authors have read and agreed to the published version of the manuscript.

Funding: This research received no external funding.

Institutional Review Board Statement: Not applicable.

Informed Consent Statement: Informed consent was obtained from all subjects involved in the study.

Data Availability Statement: The data presented in this study are openly available in the 4TU repository at https:/ / doi.org/10.4121/13213610.v2.

Acknowledgments: The authors would like to thank Julia Candy and Jeremy Faludi for reviewing the survey; the designers for pilot-testing the survey; the Ellen MacArthur Foundation, CIRCO and others in our network for spreading the survey; Maria Sääksjärvi for support in the statistical analyses; and the respondents for taking the time to complete the survey.

Conflicts of Interest: The authors declare no conflict of interest.

\section{References}

1. Bocken, N.M.P.; Bakker, C.A.; de Pauw, I.; van der Grinten, B. Product design and business model strategies for a circular economy. J. Ind. Prod. Eng. 2016, 1015, 20. [CrossRef]

2. Blomsma, F.; Brennan, G. The Emergence of Circular Economy: A New Framing around Prolonging Resource Productivity. J. Ind. Ecol. 2017, 21, 603-614. [CrossRef]

3. Ellen MacArthur Foundation. Towards a Circular Economy: Business Rationale for an Accelerated Transition; Ellen MacArthur Foundation: Cowes, UK, 2015; Volume 1.

4. European Parliamentary Research Services. The Ecodesign Directive: European Implementation Assessment; Ex-Post Evaluation Unit of the Directorate for Impact Assessment and European Added Value: Brussels, Belgium, 2017; ISBN 9789284622252.

5. Moreno, M.A.; de los Rios, C.; Rowe, Z.; Charnley, F. Guidelines for Circular Design: A Conceptual Framework. Sustainability 2016, 8, 937. [CrossRef]

6. Tam, E.; Soulliere, K.; Sawyer-Beaulieu, S. Managing complex products to support the circular economy. Resour. Conserv. Recycl. 2019, 145, 124-125. [CrossRef]

7. Den Hollander, M.C.; Bakker, C.A.; Hultink, E.J. Product Design in a Circular Economy Development of a Typology of Key Concepts and Terms. J. Ind. Ecol. 2017, 21, 517-525. [CrossRef]

8. Stahel, W.R. The Performance Economy, 2nd ed.; Palgrave Macmillan Hampshire: Hampshire, UK, $2010 ;$ ISBN 9780230584662.

9. Brezet, H.; van Hemel, C. Ecodesign: A Promising Approach to Sustainable Production and Consumption; UNEP: Paris, France, 1997.

10. De Pauw, I. Nature-Inspired Design: Strategies for Sustainable Product Development; Delft University of Technology: Delft, The Netherlands, 2015; ISBN 9789065623867.

11. Irwin, T. Transition Design: A Proposal for a New Area of Design Practice, Study, and Research. Des. Cult. 2015, 7, 229-246. [CrossRef]

12. Korhonen, J.; Honkasalo, A.; Seppälä, J. Circular Economy: The Concept and its Limitations. Ecol. Econ. 2018, 143, 37-46. [CrossRef]

13. European Environment Agency. Circular Economy in Europe-Developing the Knowledge Base; Publications Office of the European Union: Luxembourg, 2016; ISBN 9789292137199.

14. Medkova, K.; Fitfield, B. Lahti Cleantech Annual Review 2016. In Lahti Cleantech Annual Review 2016; Cura, K., Ed.; Lahti University of Applied Sciences: Lahti, Finland, 2016; pp. 32-47. ISBN 9789518272604.

15. Wiek, A.; Withycombe, L.; Redman, C.L. Key competencies in sustainability: A reference framework for academic program development. Sustain. Sci. 2011, 6, 203-218. [CrossRef] 
16. Lindahl, M. Designers' Utilization of and Requirements on Design for Environment (DfE) Methods and Tools. In Proceedings of the 4th International Symposium on Environmentally Conscious Design and Inverse Manufacturing, Tokyo, Japan, 12-14 December 2005; pp. 224-231.

17. Daalhuizen, J.J. Method Usage in Design: How Methods Function as Mental Tools for Designers. Ph.D. Thesis, Delft University of Technology, Delft, The Netherlands, 2014.

18. UNESCO. Education for Sustainable Development Goals: Learning Objectives; United Nations Education, Scientific and Cultural Organization: Paris, France, 2017.

19. De Haan, G. The development of ESD-related competencies in supportive institutional frameworks. Int. Rev. Educ. 2010, 56, 315-328. [CrossRef]

20. Rieckmann, M. Future-oriented higher education: Which key competencies should be fostered through university teaching and learning? Futures 2012, 44, 127-135. [CrossRef]

21. Kirchherr, J.; Piscicelli, L. Towards an Education for the Circular Economy (ECE): Five Teaching Principles and a Case Study. Resour. Conserv. Recycl. 2019, 150, 104406. [CrossRef]

22. Forslund, T.; Clinton, N.; Webster, K. A Global Snapshot of Circular Economy Learning Offerings in Higher Education; Ellen MacArthur Foundation: Cowes, UK, 2018.

23. Sumter, D.X.; de Koning, J.; Bakker, C.A.; Balkenende, R. Circular Economy Competencies for Design. Sustainability 2020, $12,1561$. [CrossRef]

24. Sumter, D.X.; Bakker, C.A.; Balkenende, A.R. The role of product design in creating circular business models: A case study on lease and refurbishment of baby strollers. Sustainability 2018, 10, 2415. [CrossRef]

25. Sumter, D.X.; de Koning, J.; Bakker, C.A.; Balkenende, R. Design competencies for a circular economy. In Proceedings of the 3rd PLATE Product Lifetimes and the Environment 2019, Berlin, Germany, 18-20 September 2019; Nissen, N.F., Jaeger-Erben, M., Eds.; TU Berlin University Press: Berlin, Germany, 2019; pp. 763-768.

26. De los Rios, I.C.I.C.; Charnley, F.J.S. Skills and capabilities for a sustainable and circular economy: The changing role of design. J. Clean. Prod. 2016, 160, 109-122. [CrossRef]

27. Peterson, R.A. The Process of Questionnaire Construction. In Constructing Effective Questionnaires; Sage: London, UK, 2000; pp. 13-27, ISBN 9781483349022.

28. Qualtrics, Provo, UT, USA. Available online: http:/ / www.qualtrics.com (accessed on 3 March 2020).

29. Blomsma, F.; Brennan, G. Circularity Thinking: Systems thinking for circular product and business model (re)design—Identifying waste flows and redirecting them for value creation and capture. In Designing for the Circular Economy; Charter, M., Ed.; Routledge, Taylor \& Francis Group: London, UK, 2018; pp. 133-147, ISBN 9781138081017.

30. Webster, K.; Johnson, C. Sense E Sustainability: Educating for a Circular Economy; TerrePreta: Bradford, UK, 2010; ISBN 9780955983108.

31. Whalen, K.A.; Berlin, C.; Ekberg, J.; Barletta, I.; Hammersberg, P. 'All they do is win': Lessons learned from use of a serious game for Circular Economy education. Resour. Conserv. Recycl. 2017, 135, 335-345. [CrossRef]

32. Zink, T.; Geyer, R. Circular Economy Rebound. J. Ind. Ecol. 2017, 21, 593-602. [CrossRef]

33. Köhler, A.; Bakker, C.A.; Peck, D. Materials Scarcity: A New Agenda for Industrial Design Engineering. In Proceedings of the European Roundtable for Sustainable Consumption and Production-Environmental Management for Sustainable Universities, Delft, The Netherlands, 25-29 October 2010; pp. 1-27.

34. Lilley, D.; Bridgens, B.; Davies, A.; Holstov, A. Ageing (dis)gracefully: Enabling designers to understand material change. J. Clean. Prod. 2019, 220, 417-430. [CrossRef]

35. Sauerwein, M.; Doubrovski, E.L. Local and recyclable materials for additive manufacturing: 3D printing with mussel shells. Mater. Today Commun. 2018, 15, 214-217. [CrossRef]

36. Tukker, A. Product services for a resource-efficient and circular economy-A review. J. Clean. Prod. 2015, 97, 76-91. [CrossRef]

37. Bocken, N.M.P.; Strupeit, L.; Whalen, K.; Nußholz, J. A review and evaluation of circular business model innovation tools. Sustainability 2019, 11, 2210. [CrossRef]

38. Nußholz, J.L.K. A circular business model mapping tool for creating value from prolonged product lifetime and closed material loops. J. Clean. Prod. 2018, 197, 185-194. [CrossRef]

39. Poppelaars, F.A.; Bakker, C.A.; van Engelen, J. Design for divestment in a circular economy: Stimulating voluntary return of smartphones through design. Sustainability 2020, 12, 1488. [CrossRef]

40. Kirchherr, J.; Reike, D.; Hekkert, M. Conceptualizing the circular economy: An analysis of 114 definitions. Resour. Conserv. Recycl. 2017, 127, 221-232. [CrossRef]

41. Geissdoerfer, M.; Savaget, P.; Bocken, N.M.P.; Hultink, E.J. The Circular Economy-A new sustainability paradigm? J. Clean. Prod. 2016, 143, 757-768. [CrossRef]

42. Brown, P.; Bocken, N.; Balkenende, R. Why Do Companies Pursue Collaborative Circular Oriented Innovation? Sustainability 2019, 11, 635. [CrossRef]

43. Gaziulusoy, A.I.; Ryan, C. Roles of design in sustainability transitions projects: A case study of Visions and Pathways 2040 project from Australia. J. Clean. Prod. 2017, 162, 1297-1307. [CrossRef]

44. Ritzén, S.; Sandström, G.Ö. Barriers to the Circular Economy-Integration of Perspectives and Domains. Procedia CIRP 2017, 64, 7-12. [CrossRef] 
45. Rizos, V.; Behrens, A.; Kafyeke, T.; Hirschnitz-Garbers, M.; Ioannou, A. The Circular Economy: Barriers and Opportunities for SMEs; CEPS: Brussels, Belgium, 2015.

46. Wiek, A.; Bernstein, M.J.; Foley, R.W.; Cohen, M.; Forrest, N.; Kuzdas, C.; Kay, B.; Withycombe Keeler, L. Operationalising Competencies in Higher Education for Sustainable Development. In Handbook of Higher Education for Sustainable Development; Barth, M., Michelsen, G., Rieckmann, M., Thomas, I., Eds.; Routledge: London, UK, 2016; pp. 241-260. 